\title{
Modeling of Chill Down in Cryogenic Transfer Lines
}

\author{
Matthew F. Cross ${ }^{*}$ \\ University of Connecticut, Storrs, Connecticut 06269-3139 \\ Alok K. Majumdar ${ }^{y}$ \\ Marshall Space Flight Center, Huntsville, Alabama 35812 \\ John C. Bennett, Jr. and Ramesh B. Malla 5 \\ University of Connecticut, Storrs, Connecticut 06269-3139
}

A numerical model to predict chill down in cryogenic transfer lines has been developed. Three chill down cases using hydrogen as the working fluid are solved: 1) a simplified model amenable to analytical solution, 2) a realistic model of superheated vapor flow, and 3 ) a realistic model of initially subcooled liquid flow. The first case compares a numerical model with an analytical solution with very good agreement between the two. Additionally, the analytical solution provides a convenient way to look at parametric effects on the chill down. The second and third cases are numerical models which provide temperature histories of the fluid and solid tube wall during chill down as well as several other quantities of interest such as pressure and mass flow rate. Of great interest is the ability to predict accurate values of chill down time (the time required to achieve steady-state cryogenic flow). The models predict that a 26 in. long, 3/16 in. ID aluminum tube has a shorter chill down time $(\approx 100 \mathrm{sec})$ and uses less hydrogen with superheated vapor flow than with initially subcooled liquid flow ( $>200$ sec for chill down).

"Graduate Research Assistant (Ph.D. Candidate), Department of Mechanical Engineering, U-3139.

Aero Space Technologist, Thermodynamics and Heat Transfer Group, Member AIAA.

Associate Professor, Department of Mechanical Engineering, U-3139.

Associate Professor, Department of Civil and Environmental Engineering, U-37, Senior Member AIAA. 


\section{Nomenclature}

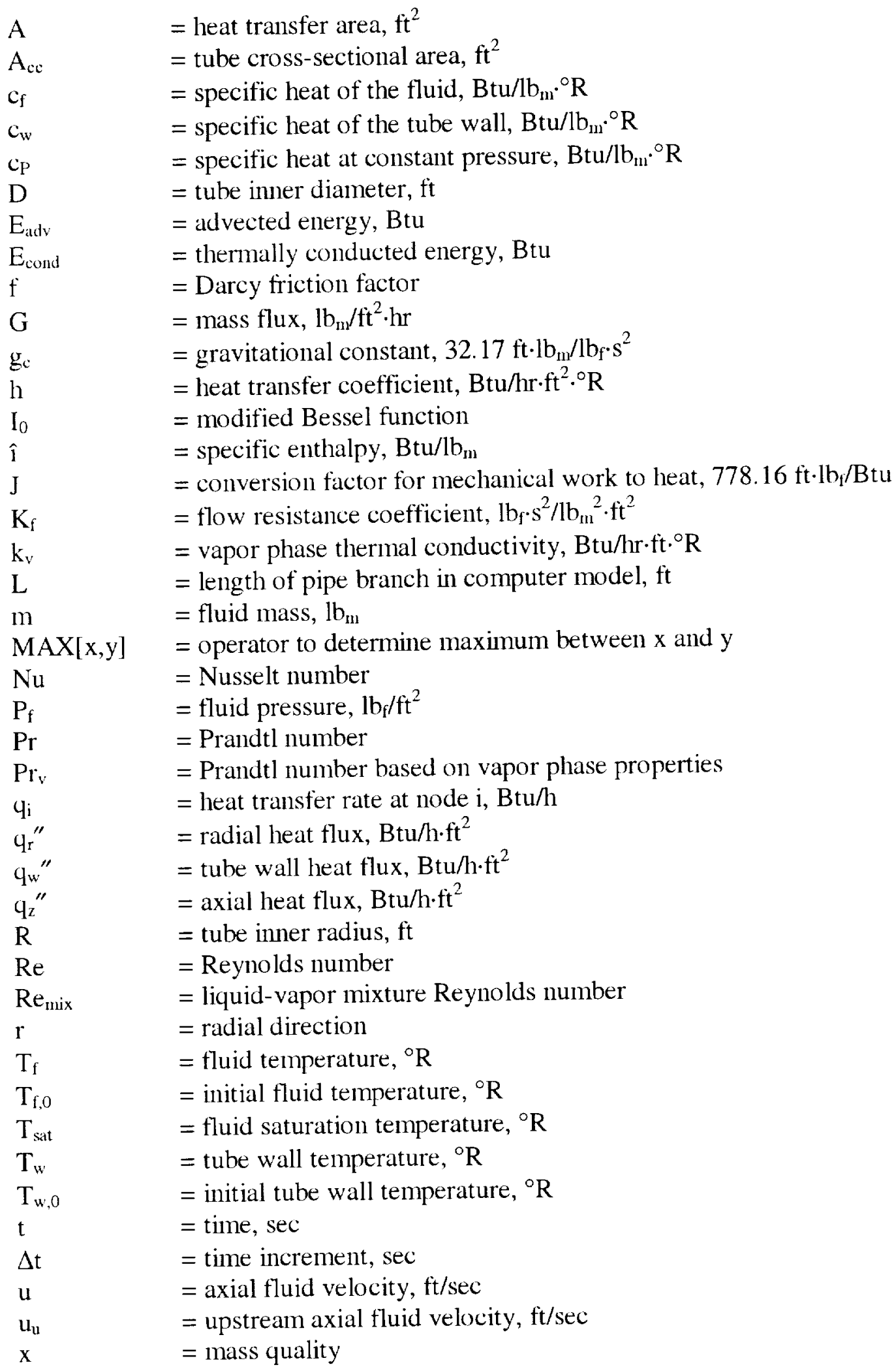




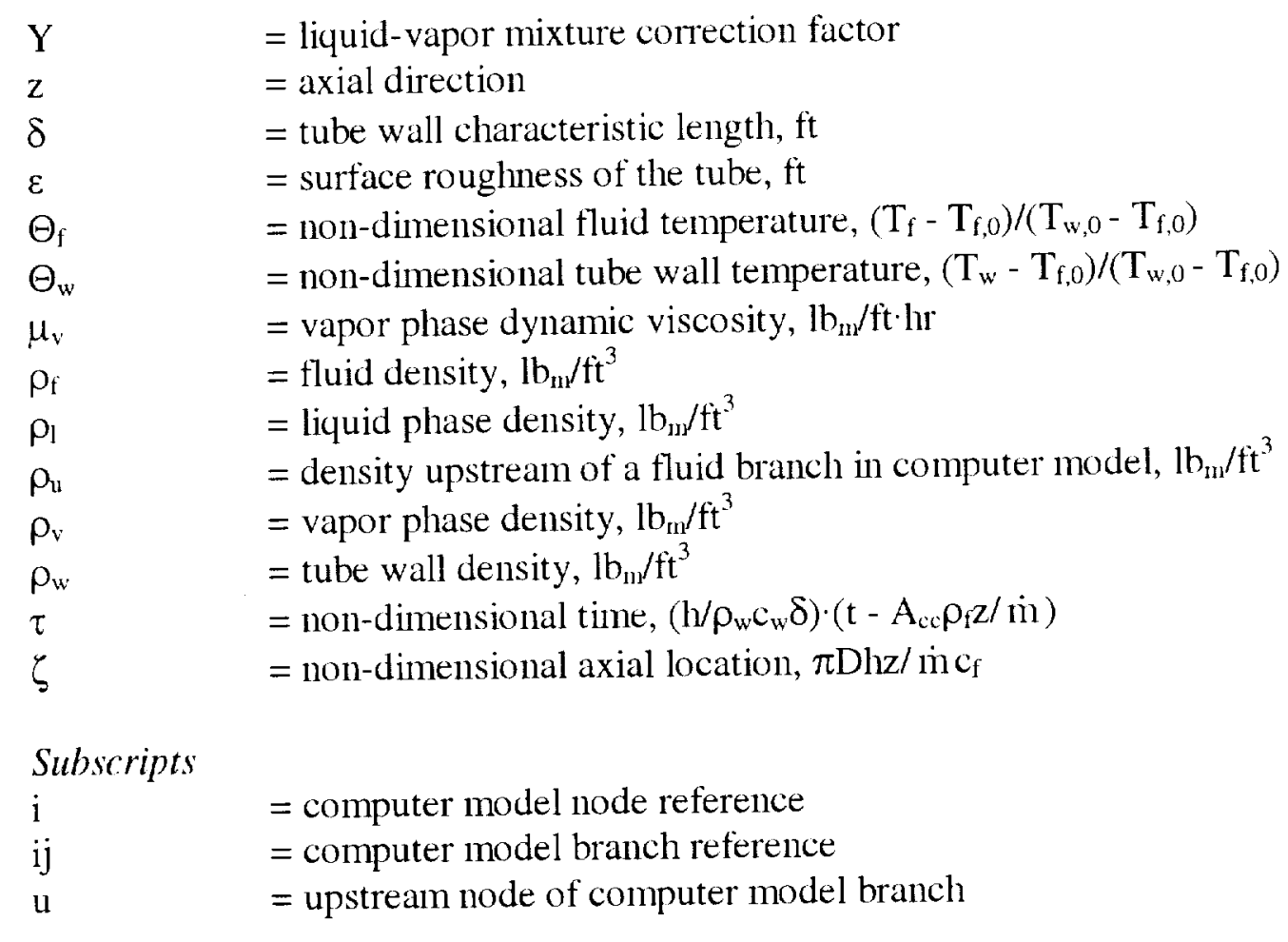

\section{Superscripts}

$\left({ }^{\prime}\right) \quad=$ over-dot indicates time rate of change

\section{Introduction}

The operation of a cryogenic propulsion system requires transfer line chill down before establishing a steady flow of cryogenic fluid between various system components. Cryogenic transfer line chill down is a transient heat transfer problem that involves rapid heat exchange from a solid structure to a fluid with phase change. It is necessary to know how long it takes to chill down a given transfer line for satisfactory operation.

When liquid cryogen, for example hydrogen, at saturation temperature $\left(36.5^{\circ} \mathrm{R}\right.$ at 1 atm.) begins flowing through a tube initially at ambient temperature $\left(540^{\circ} \mathrm{R}\right)$ the liquid instantly vaporizes near the tube wall. Thus a cross-section of the flow will have an outer vapor ring with a saturated liquid core. As the flow moves downstream, the liquid core 
evaporates and the vapor becomes superheated. As the tube wall cools, the liquid core penetrates further and further downstream. Eventually, the tube becomes filled with liquid. Reduction in fluid density by vaporization causes the average flow velocity to increase significantly. Prediction of chill down time requires modeling of these transient phenomena and understanding of how they affect heat transfer from the tube wall to the flowing cryogen.

Burke et al. ${ }^{1}$ studied chill down of $60 \mathrm{ft} ., 100 \mathrm{ft}$. and $175 \mathrm{ft}$. long, $2 \mathrm{in}$. outer diameter (OD) stainless steel lines by flowing liquid nitrogen. A model to predict chill down time was developed by treating the entire line as a single control volume. This lumped system provides a simple estimate of chill down time but lacks accuracy due to its broad assumptions and averaging of fluid properties and flow rates over the chill down time. Furthermore, this method cannot be used to calculate instantaneous fluid and transfer line wall temperatures.

$\mathrm{Chi}^{2}$ looked at chill down of a $26 \mathrm{in.}$ long, $3 / 16 \mathrm{in}$. inner diameter (ID) aluminum tube using saturated liquid hydrogen as the working fluid. An analytical model of the chill down (presented below) was developed under the assumptions of constant flow rate, constant heat transfer coefficient, constant fluid properties, homogeneous fluid flow and film-boiling dominated heat transfer. The assumption of constant flow rate is not very realistic since usually the transfer line inlet and exit pressures are set while the flow rate may vary greatly according to the flow condition. The assumptions of constant heat transfer coefficient and constant fluid properties are highly restrictive but can provide useful estimates of temperature and chill down time. The last two assumptions are 
idealizations but are widely applicable and produce reasonable results when properly applied.

Steward, et $a l^{3}$ modeled chill down numerically using a finite-difference formulation of the one-dimensional, unsteady mass, momentum and energy equations. The model results agree well with experimental results of chill down of a $200 \mathrm{ft}$. long, $0.625 \mathrm{in}$ ID, $0.750 \mathrm{in.}$ OD copper tube using liquid nitrogen and liquid hydrogen as the working fluids. Heat transfer coefficients were determined using superposition of singlephase forced convection correlations and pool boiling correlations for both nucleate and film boiling. While this type of correlation for film boiling may be acceptable under low flow rate/low quality conditions, more recent publications recommend the modified Dittus-Boelter type correlation for a wide range of flow conditions. ${ }^{4,5,6}$ It is believed that improved accuracy and greater generality of application will be achieved through implementation of a modified Dittus-Boelter type correlation for flow film boiling. Correct modeling of flow film boiling is especially crucial with cryogenic hydrogen since film boiling occurs to as low as a tube wall to fluid saturation temperature difference of approximately $20^{\circ} \mathrm{R}$ resulting in a large portion of the chill down occurring under film boiling.

Complete analytical modeling of the complex heat transfer phenomena occurring during chill down is not possible. This paper presents analytical and computer models of the cryogenic transfer line chill down process described in five sections. The first section is about modeling the chill down process analytically using energy conservation. The conservation equation is simplified leading to a closed form solution. This simplified case gives insight into parametric effects on the chill down process as well as serving as a 
benchmark for the computer solution. The second section discusses theoretical development of a heat transfer coefficient for two-phase heat transfer between the tube wall and fluid. The computer model is described in the third section and results from the computer model are given in the fourth section. Finally, the fifth section presents some conclusions drawn from the study.

\section{Analytical Model}

The physical problem modeled is a fluid entering a circular tube at temperature $\mathrm{T}_{\mathrm{f}, 0}$. The tube wall is initially at temperature $\mathrm{T}_{\mathrm{w}, 0}$. Transient heat transfer occurs between the tube and the fluid when $T_{w} \neq T_{\mathrm{f}}$. The flow pattern is approximated as one-dimensional with fluid velocity in the axial direction only. Figure 1 shows an energy balance on a fluid control volume where the over dots on the energy terms indicate time rate of change.

Conservation of energy for the control volume states that:

$$
\left\{\begin{array}{c}
\text { rate of } \\
\text { accumulation } \\
\text { of energy }
\end{array}\right\}=\left\{\begin{array}{c}
\text { net rate of } \\
\text { energy in by } \\
\text { advection }
\end{array}\right\}+\left\{\begin{array}{c}
\text { net rate of } \\
\text { energy in by } \\
\text { conduction }
\end{array}\right\}-\left\{\begin{array}{l}
\text { net rate of work } \\
\text { done by system } \\
\text { on surroundings }
\end{array}\right\}
$$

Equation (1) can be stated mathematically in cylindrical coordinates neglecting viscous dissipation as (see Ref. 7, for example, for derivation)

$$
\rho_{\mathrm{f}} \mathrm{c}_{\mathrm{f}}\left(\frac{\partial \mathrm{T}_{\mathrm{f}}}{\partial \mathrm{t}}+\mathrm{u} \frac{\partial \mathrm{T}_{\mathrm{f}}}{\partial \mathrm{z}}\right)=-\left[\frac{1}{\mathrm{r}} \frac{\partial}{\partial \mathrm{r}}\left(\mathrm{rq}_{\mathrm{r}}^{\prime \prime}\right)+\frac{\partial \mathrm{q}_{\mathrm{z}}^{\prime \prime}}{\partial \mathrm{z}}\right]-\mathrm{T}_{\mathrm{f}}\left(\frac{\partial \mathrm{P}_{\mathrm{f}}}{\partial \mathrm{T}_{\mathrm{f}}}\right)_{\mathrm{p}} \frac{\partial \mathrm{u}}{\partial \mathrm{z}}
$$

Following the analysis of $\mathrm{Chi}^{2}$, Eq. (2) is simplified for application to the problem of chill down in cryogenic transfer lines using the following assumptions: 
- Axial conduction in the fluid may be neglected.

- Flow work may be neglected.

- Fluid mass flow rate is constant.

- Heat transfer coefficient (h) is constant.

- Constant solid and fluid properties

By expressing $\mathrm{q}_{\mathrm{r}}^{\prime \prime}$ in terms of Newton's law of cooling, and integrating over the tube radius, Eq. (2) may be expressed in terms of non-dimensional variable $\zeta[\pi \mathrm{Dhz} /$

$\left.\dot{m} c_{i}\right]$ as

$$
-\left(\frac{\partial T_{f}}{\partial \zeta}\right)_{\tau}=T_{f}-T_{w}
$$

Using a lumped-capacitance model, local wall heat flux may be expressed in terms of non-dimensional variable $\tau\left[\left(\mathrm{h} / \rho_{\mathrm{w}} \mathrm{c}_{\mathrm{w}} \delta\right) \cdot\left(\mathrm{t}-\mathrm{A}_{\mathrm{cc}} \rho_{\mathrm{f}} \mathrm{z} / \mathrm{m}\right)\right]$ as

$$
\left(\frac{\partial \mathrm{T}_{w}}{\partial \tau}\right)_{\xi}=\mathrm{T}_{\mathrm{f}}-\mathrm{T}_{\mathrm{w}}
$$

Equations (3) and (4) together with the initial and boundary conditions

$$
\begin{aligned}
& \text { at } \zeta=0, \quad T_{\mathrm{f}}=\mathrm{T}_{\mathrm{f}, 0} \quad \text { for all } \tau \\
& \text { at } \tau=0, \quad \mathrm{~T}_{\mathrm{w}}=\mathrm{T}_{\mathrm{w}, 0} \quad \text { for all } \zeta
\end{aligned}
$$

may be solved to give $\mathrm{e}^{2,8}$

$$
\frac{T_{w}-T_{w, 0}}{T_{t, 0}-T_{w, 0}}=\int_{0}^{\tau} e^{-(\tau+\zeta)} I_{0}(\sqrt{4 \tau \zeta}) d \tau
$$

and

$$
\frac{T_{f}-T_{f, 0}}{T_{w, 0}-T_{f, 0}}=\int_{0}^{\zeta} e^{-(\tau+\zeta)} I_{0}(\sqrt{4 \tau \zeta}) d \zeta
$$


Figure 2 shows how non-dimensional tube wall temperature varies with nondimensional time according to a slightly rearranged version of Eq. (5) (see nomenclature for definition of $\Theta_{w}$ ). For a fixed value of $z, T_{w}$ decreases with time and approaches $T_{f, 0}$. The effect of varying the parameter $\zeta$ on the tube wall cooling rate is also shown with the four different curves: the tube wall cools more slowly as $\zeta$ increases. Figure 3 shows how non-dimensional fluid temperature varies with non-dimensional tube axial location according to Eq. (6). For a fixed value of time, $T_{f}$ increases with axial location. For a fixed value of $\zeta, T_{f}$ approaches $T_{f, 0}$ at large time values.

\section{Heat Transfer Coefficients}

For large differences in tube wall temperature $\left(\mathbf{T}_{\mathrm{w}}\right)$ and initial fluid temperature $\left(T_{f, 0}\right)$, film boiling occurs immediately at the entrance of the tube. ${ }^{9}$ The mass quality $(x)$ of the fluid increases as it travels through the tube eventually becoming superheated vapor. In the entrance region of the tube, liquid is surrounded by a vapor film in the socalled inverted annular flow pattern. As the liquid-vapor mixture proceeds downstream, the liquid phase vaporizes and the flow eventually becomes pure vapor.

For turbulent single-phase flow, the Dittus-Boelter equation provides a correlation of Nusselt number as a function of Reynolds number and Prandtl number

$$
\mathrm{Nu}=0.023 \operatorname{Re}^{0.8} \operatorname{Pr}^{0.4}
$$


The above correlation may be applied to a homogeneous model of the two-phase flow occurring in the tube using mean fluid properties (see Ref. 10 for derivation). One such correlation resulting from this type of analysis is that given by Miropolskii ${ }^{11,12}$

$$
\mathrm{Nu}=0.023\left(\operatorname{Re}_{\text {ruix }}\right)^{0.8}\left(\operatorname{Pr}_{\mathrm{v}}\right)^{0.8}(\mathrm{Y})
$$

where

$$
\begin{gathered}
\mathrm{Nu}=\frac{\mathrm{hD}}{\mathrm{k}_{\mathrm{v}}} \\
\operatorname{Re}_{\text {mix }}=\frac{\mathrm{GD}}{\mu_{\mathrm{v}}}\left[\mathrm{x}+\left(\frac{\rho_{\mathrm{v}}}{\rho_{1}}\right)(1-\mathrm{x})\right] \\
\operatorname{Pr}_{\mathrm{v}}=\left(\frac{\mathrm{c}_{\mathrm{P}} \mu}{\mathrm{k}}\right)_{v} \\
\mathrm{Y}=1-0.1\left(\frac{\rho_{\mathrm{l}}}{\rho_{\mathrm{v}}}-1\right)^{0.4}(1-\mathrm{x})^{0.4}
\end{gathered}
$$

Several researchers have applied a modified Dittus-Boelter formulation to correlate heat transfer data. A comprehensive review of correlations of this type may be found in Ref. 13.

Since $\operatorname{Pr}_{v}$ is close to unity under saturated conditions, this term does not have a significant effect on the value of $\mathrm{Nu}$. Therefore, in order to have asymptotic agreement of Eq. (8) with Eq. (7) when $x=1$ (saturated vapor flow), the exponent on $\mathrm{Pr}_{\mathrm{v}}$ in Eq. (8) is replaced with 0.4 . Thus, the proposed liquid-vapor region Nusselt number is

$$
\mathrm{Nu}=0.023\left(\operatorname{Re}_{\text {mix }}\right)^{0.8}\left(\operatorname{Pr}_{v}\right)^{0.4}(Y)
$$




\section{Computer Models}

Numerical modeling of boiling heat transfer in a confined tube requires the solution of unsteady mass, momentum and energy conservation equations in conjunction with a thermodynamic equation of state and correlations for boiling heat transfer. The Generalized Fluid System Simulation Program (GFSSP) ${ }^{14}$ was used to develop a computational model of this process. In GFSSP, the conservation equations are first expressed in finite volume form for a flow network. A flow network consisting of fluid nodes and branches is shown in Fig. 4. At boundary nodes, pressures and temperatures are known. At internal nodes and branches, the variables are calculated by solving the conservation equations.

Mass and energy conservation equations are written for internal nodes to determine the pressures and temperatures. The momentum conservation equations are written for branches to determine the flow rates. The mass conservation equation for a typical internal node $\mathrm{i}$ can be expressed as:

$$
\frac{m_{i, 1+\Delta t}-m_{i, t}}{\Delta t}=\sum_{j=1}^{j=n} \dot{m}_{i j}
$$

A typical intermal node $\mathrm{i}$ is comnected to the neighboring nodes $\mathrm{j}$ through branch $\mathrm{ij}$ as shown in Fig. 5.

The energy conservation equation for node i shown in Fig. 5 can be expressed mathematically as shown in Eq. (15).

$$
\frac{m\left(\hat{\imath}-\frac{p}{\rho J}\right)_{t+\Delta t}-m\left(\hat{\imath}-\frac{p}{\rho J}\right)}{\Delta t}=\sum_{j=1}^{j=n}\left\{\operatorname{MAX}\left[-\dot{m}_{i j}, 0\right] \hat{\mathfrak{t}}_{j}-\operatorname{MAX}\left[\dot{m}_{i j}, 0\right] \hat{\mathfrak{t}}_{i}\right\}+\mathrm{q}_{i}
$$

where 


$$
\mathrm{q}_{\mathrm{i}}=\mathrm{hA}\left(\mathrm{T}_{\mathrm{w}}-\mathrm{T}_{\text {sat }}\right)
$$

and $h$ is determined from Eq. (13).

The momentum conservation equation for branch ij can be expressed mathematically as shown in Eq. (17).

$$
\frac{\left(m_{\left.u_{t+\Delta t}-m_{u_{i}}\right)}\right.}{g_{c} \Delta t}+\frac{\dot{m}_{i j}}{g_{c}}\left(u_{i j}-u_{u}\right)=\left(P_{f, i}-P_{i, j}\right) A-K_{i} \dot{m}_{i j}\left|\dot{m}_{i j}\right| A
$$

where

$$
\mathrm{K}_{\mathrm{f}}=\frac{8 \mathrm{fL}_{\mathrm{ij}}}{\rho_{\mathrm{u}} \pi^{2} \mathrm{D}_{\mathrm{ij}}^{5} \mathrm{~g}_{\mathrm{c}}}
$$

and the Darcy friction factor $f$ is determined from the Colebrook Equation expressed as

$$
\frac{1}{\sqrt{\mathrm{f}}}=-2 \log \left[\frac{\varepsilon}{3.7 \mathrm{D}}+\frac{2.51}{\operatorname{Re} \sqrt{\mathrm{f}}}\right]
$$

Equations 14 through 19 are solved numerically. The details of the numerical method appear in Ref. 14. All of the models presented here have 30 nodes and use hydrogen as the working fluid. Other model parameters are given in Table 1.

Equations 14 through 19 are solved numerically in GFSSP. ${ }^{14}$ GFSSP uses a combination of the successive substitution method and the Newton-Raphson method to solve these equations. In this scheme, the mass and momentum conservation equations are solved by the Newton-Raphson method while the energy and specie conservation equations are solved by the successive substitution method. The underlying principle for making such a division is that the equations that are more strongly coupled are solved by the Newton-Raphson method. The equations that are not strongly coupled with the other set of equations are solved by the successive substitution method. Thus, the computer 
memory requirement can be significantly reduced while maintaining superior numerical convergence characteristics.

In the iterative loop, mass and momentum conservation equations and the equation of state are solved by the Newton-Raphson method. The energy and specie conservation equations are then solved by the successive substitution method. Finally, the density and other thermodynamic and thermophysical properties and the flow resistance coefficient, $\mathrm{K}_{\mathrm{f}}$ are calculated. The iterative cycle is terminated when the normalized maximum correction, $\Delta_{\max }$, is less than the convergence criterion, $\mathrm{C}_{\mathrm{c}} \cdot \Delta_{\max }$ is determined from

$$
\Delta_{\text {IILix }}=\operatorname{MAX}\left|\sum_{i=1}^{N_{E}} \frac{\Phi_{i}}{\Phi_{i}}\right|
$$

where $N_{E}$ is the total number of equations and $\Phi$ is the dependent variable (pressure and resident mass in node and flow rate in branch). The convergence criterion is set to 0.01 in all models presented in this paper.

\section{Results}

\section{Analytical Model}

Figure 6 shows a comparison of fluid and wall temperatures calculated using the analytical model (Eqs. (5) \& (6)) with temperatures determined by a GFSSP numerical model (Model 1 in Table. 1). As indicated in Table 1, the simulation was done using a constant h. Major differences between the analytical and numerical simulations are that fluid properties and mass flow rate are allowed to vary in the latter. To approximately compensate for variable mass flow rate, a running average of the mass flow rate 
calculated in the computer solution was iteratively applied to the analytical solution.

Despite these differences, there is good overall agreement between the two methods. The agreement between the analytical and numerical models indicates that the numerical solution to the chill down problem is reliable.

\section{Numerical Model - Superheated Vapor Flow (Model 2)}

To add another level of sophistication towards modeling a fully two-phase flow, superheated vapor flow was modeled. In this case, the h for heat transfer between the tube wall and passing fluid is allowed to vary according to Eq. (13). Since $x \geq 1$, Eq. (13) and Eq. (7) are equal for this case. The temperatures vs. time results for this simulation are shown in Fig. 7. It is seen that fluid temperature remains relatively low near the inlet but increases close to the tube wall temperature near the exit. Chill down is achieved after approximately 100 seconds. Figure 8 indicates that h increases with axial location until chill down is achieved. Analysis of numerical model output data not shown here shows that Reynolds number decreases with axial position but the large increase in fluid thermal conductivity with temperature causes $h$ to increase axially. $h$ increases uniformly with time near the tube entrance but there is some fluctuation at downstream locations. This effect is caused by a combination of increasing Reynolds number and decreasing fluid thermal conductivity according to Eq. (7). The effect of Prandtl number on h is small. Figure 9 shows that the hydrogen mass flow rate increases until chill down is nearly achieved.

\section{Numerical Model - Subcooled Liquid Flow (Model 3)}

This simulation models the more typical case of cryogenic fluid entering as a subcooled liquid during transfer. The subcooled liquid changes to vapor downstream of 
the tube entrance. The liquid front propagates downstream as the tube cools. Figure 10 shows temperature vs. time for this simulation. Initially there is significant sensible heating of the fluid near the exit of the tube but the temperature quickly drops to saturation temperature. Mass quality data (not shown here) from the simulation elucidate this trend by showing the fluid to be initially superheated near the exit and then quickly becoming saturated. The fluid is saturated over most of the tube's length during chill down. The tube wall temperatures display the exact opposite trend in this case compared to the single-phase vapor case (Model 2), i.e. the exit cools faster than the entrance. This trend is explained by the large increase in $\mathrm{h}$ with axial location (see Fig. 11). According to Eq. (13), h increases with mass quality. Thus, in the two-phase region, because mass quality increases as the fluid moves downstream $\mathrm{h}$ also increases axially. Fluctuations of $\mathrm{h}$ with respect to time are explained with the same reasoning given in the superheated case (Model 2). Figure 12 shows that the hydrogen mass flow rate increases and then reaches steady-state. Steady mass flow rate for this case occurs earlier on in the chill down than in the superheated case when considered as a portion of the total chill down time.

\section{Conclusions}

Figure 10 indicates that for the case of initially subcooled liquid entering the tube, the exit cools faster than the entrance. This phenomenon was also observed by Graham et al. ${ }^{15}$ in a series of tube flow film boiling experiments using hydrogen with constant wall heat flux. This is opposite the trend for single-phase flow heat transfer. 
The time to achieve non-dimensional tube wall temperature $\Theta_{w}=0$ near the tube exit (slowest cooling end) is approximately 100 seconds for the superheated hydrogen vapor flow case (Model 2). The mass of fluid passed through the tube over this time period is $0.263 \mathrm{lb}_{\mathrm{m}}$. In comparison, $2.474 \mathrm{lb}_{\mathrm{m}}$ of fluid is passed through the tube in the case of initially subcooled liquid hydrogen over the same time period resulting in $\Theta_{w}=$ 0.21 near the tube entrance (slowest cooling end). This indicates that the subcooled chill down case expends 9.41 times the fluid used in the superheated vapor case to achieve less chill down. This result has important implications when reduction in chill down time and cryogen expenditure during chill down are primary design considerations.

\section{Acknowledgment}

This work was supported by a fellow ship awarded to the first author under the NASA Experimental Program to Stimulate Competitive Research (EPSCoR) preparation grant in Connecticut (Grant NCC5-390). The work was conducted at Marshall Space Flight Center, Huntsville, AL in the ED25/Thermodynamics and Heat Transfer Group.

\section{References}

${ }^{1}$ Burke, J. C., Byrnes, W. R., Post, A. H., and Ruccia, F. E., "Pressurized Cooldown of Cryogenic Transfer Lines," Advances in Cryogenic Engineering, Vol. 4, Plenum Press, New York, 1960, pp. 378-394.

${ }^{2}$ Chi, J. W. H., "Cooldown Temperatures and Cooldown Time During Mist Flow," Advances in Cryogenic Engineering, Vol. 10, Plenum Press, New York, 1965, pp. 330340. 
${ }^{3}$ Steward, W. G., Smith, R. V., and Brennan, J. A., "Cooldown Transients in Cryogenic Transfer Lines," Advances in Cryogenic Engineering, Vol. 15, Plenum Press, New York, 1970, pp. 354-363.

${ }^{4}$ Carey, V. P., Liquid-Vapor Phase-Change Phenomena, Taylor \& Francis, 1992, pp. 540-548.

${ }^{5}$ Collier, J. G., Convective Boiling and Condensation, McGraw-Hill, London, 1972 , pp. 219-227.

${ }^{6}$ Hewitt, G. F., "Boiling," Handbook of Heat Transfer, $3^{\text {rd }}$ ed., W. M. Rohsenow, J. P. Hartnett and Y. I. Cho, ed., McGraw-Hill, New York, 1998, chpt.15, pp. 133-134.

${ }^{7}$ Bird, R. B., Stewart, W. E., and Lightfoot, E. N., Transport Phenomena, Wiley, New York, 1960, pp. 310-320.

${ }^{8}$ Mickley, H. S., Sherwood, T. K., and Reed, C. E., Applied Mathematics in Chemical Engineering, $2^{\text {nd }}$ ed., McGraw-Hill, New York, 1957, pp. 303-307.

${ }^{9}$ Carey, V. P., Liquid-Vapor Phase-Change Phenomena, Taylor \& Francis, 1992, pp. 483-490.

${ }^{10}$ Carey, V. P., Liquid-Vapor Phase-Change Phenomena, Taylor \& Francis, 1992, pp. $546-547$.

${ }^{11}$ Collier, J. G., Convective Boiling and Condensation, McGraw-Hill, London, 1972, p. 226.

${ }^{12}$ Miropolskii, Z. L., "Heat Transfer in Film Boiling of a Steam-Water Mixture in Steam Generating Tubes," Teploenergetika, Vol. 10, 1963, pp. 49-52; transl. AEC-tr6252,1964 
${ }^{13}$ Collier, J. G., "Heat transfer in the Postdryout Region and During Quenching and Reflooding," Handbook of Multiphase Systems, G. Hetsroni, ed., Hemisphere,

Washington, 1982, chpt.6, pp.142-172.

${ }^{14}$ Majumdar, A. K., "A Second Law Based Unstructured Finite Volume Procedure for Generalized Flow Simulation,” AIAA Paper 99-0934, Jan. 1999.

${ }^{15}$ Graham, R. W., Hendricks, R. C., Hsu, Y. Y., and Friedman, R., "Experimental Heat Transfer and Pressure Drop of Film Boiling Hydrogen Flowing Through a Heated Tube," Advances in Cryogenic Engineering, Vol. 6, Plenum Press, New York, 1961, pp. $517-524$. 
Table 1 Computer model paraneters.

\begin{tabular}{|c|c|c|c|c|c|c|c|c|c|}
\hline & Tube & Inside & Outside & $\mathrm{Na}$ & $\begin{array}{l}\text { Inlet } \\
\text { Pressurt }\end{array}$ & $\begin{array}{c}\text { Exit } \\
\text { Pressure }\end{array}$ & $\begin{array}{c}\text { Inlet } \\
\text { Temperature }\end{array}$ & $\begin{array}{c}\text { Inlet } \\
\text { Condition }\end{array}$ & $\begin{array}{c}\text { Condition } \\
\text { on } \mathrm{h}\end{array}$ \\
\hline Model & $\begin{array}{c}\text { Length } \\
\text { (in.) }\end{array}$ & $\begin{array}{c}\text { Diameter } \\
\text { (in.) }\end{array}$ & $\begin{array}{c}\text { Diameter } \\
\text { (in.) }\end{array}$ & Material P. & $\begin{array}{c}\text { Pressur } \\
\text { (psi) }\end{array}$ & $\begin{array}{c}\text { Pressure } \\
\text { (psi) }\end{array}$ & $\left({ }^{\circ} \mathrm{R}\right)$ & & \\
\hline 1 & 26 & $3 / 16$ & $1 / 2$ & Aluminum & 14.7 & 13.318 & 59.67 & superheated & constant \\
\hline 2 & 26 & $3 / 16$ & $\overline{1 / 2}$ & Aluminum & 14.7 & 13.318 & 59.67 & superheated & Eq. (13) \\
\hline 3 & 26 & $3 / 16$ & $1 / 2$ & Aluminum & 14.7 & 13.318 & 34.67 & subcooled & $\mathrm{Eg} .(13)$ \\
\hline
\end{tabular}




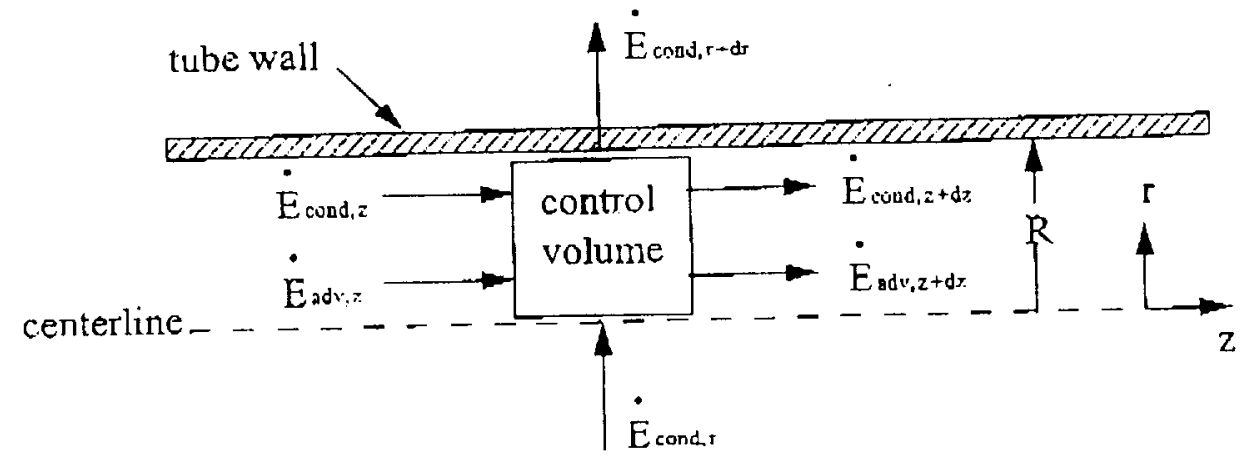

Fig. 1 Energy balance on control volume for internal tube flow. 
1

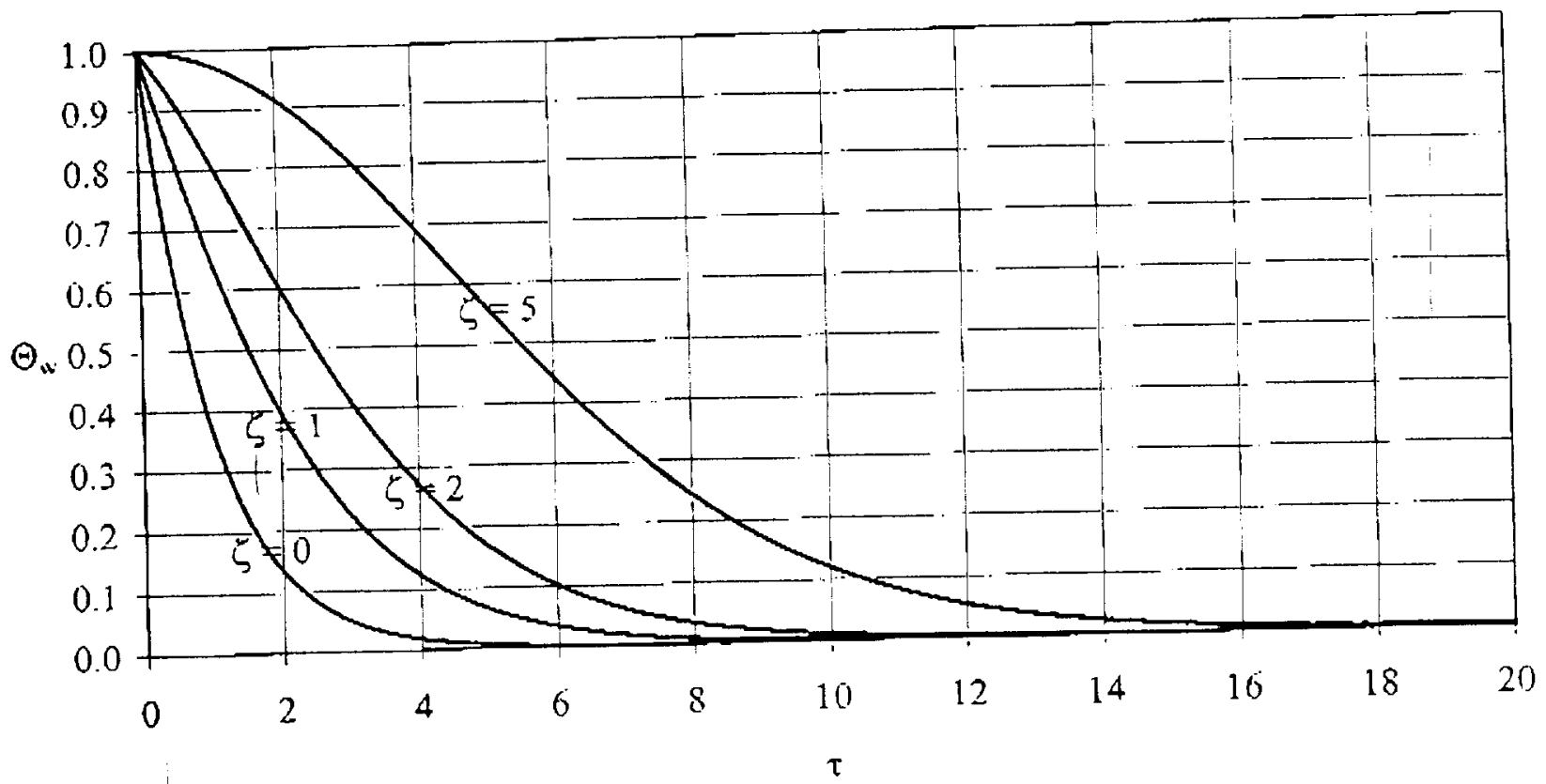

Fig. 2 Non-dimensional tube wall cooling rate for single-pbase flow for some values of nondimensional axial location. 


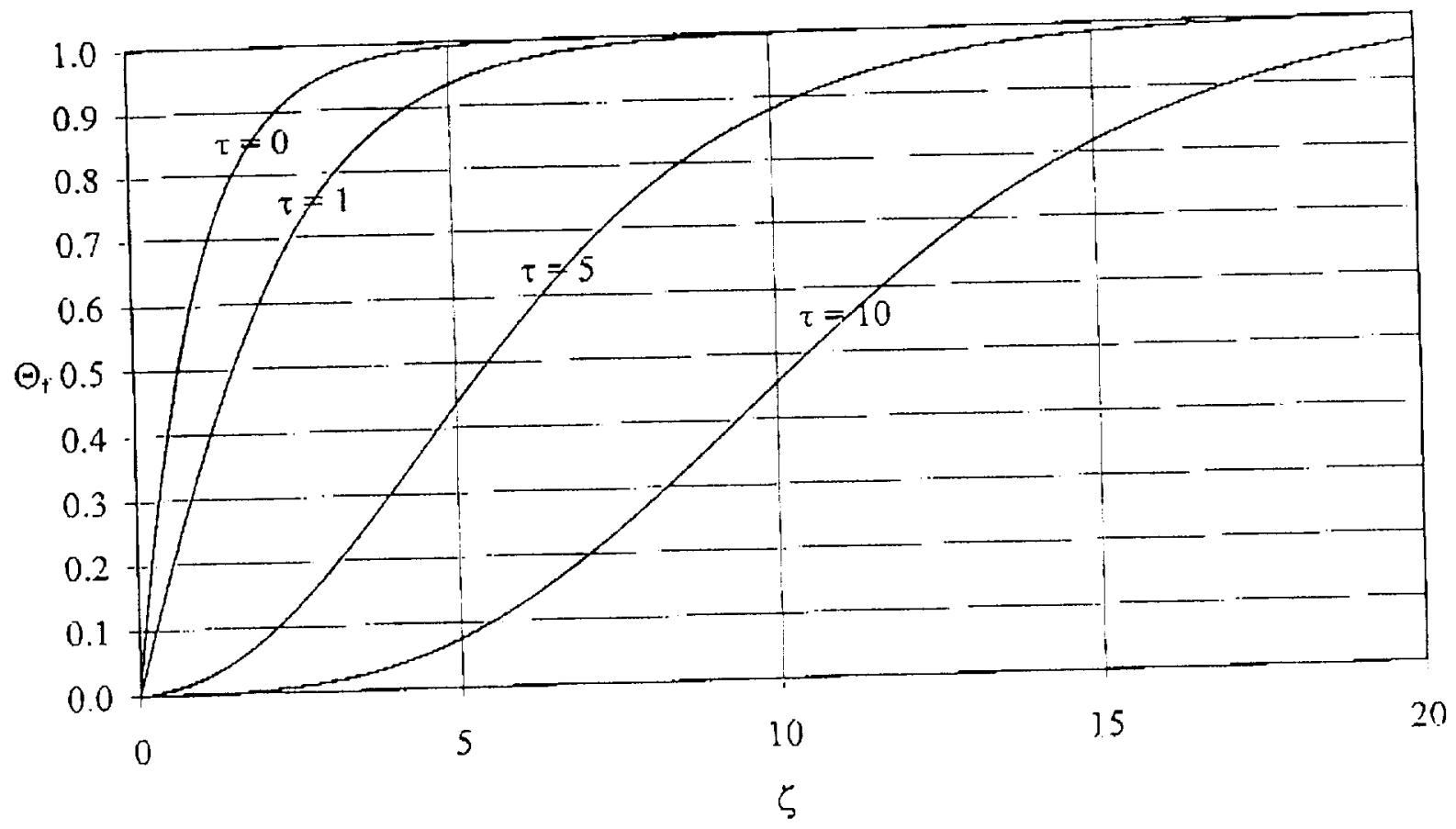

Fig. 3 Non-dimensional fluid temperature vs. non-dimensional tube axial location for some values of non-dimensional time. 


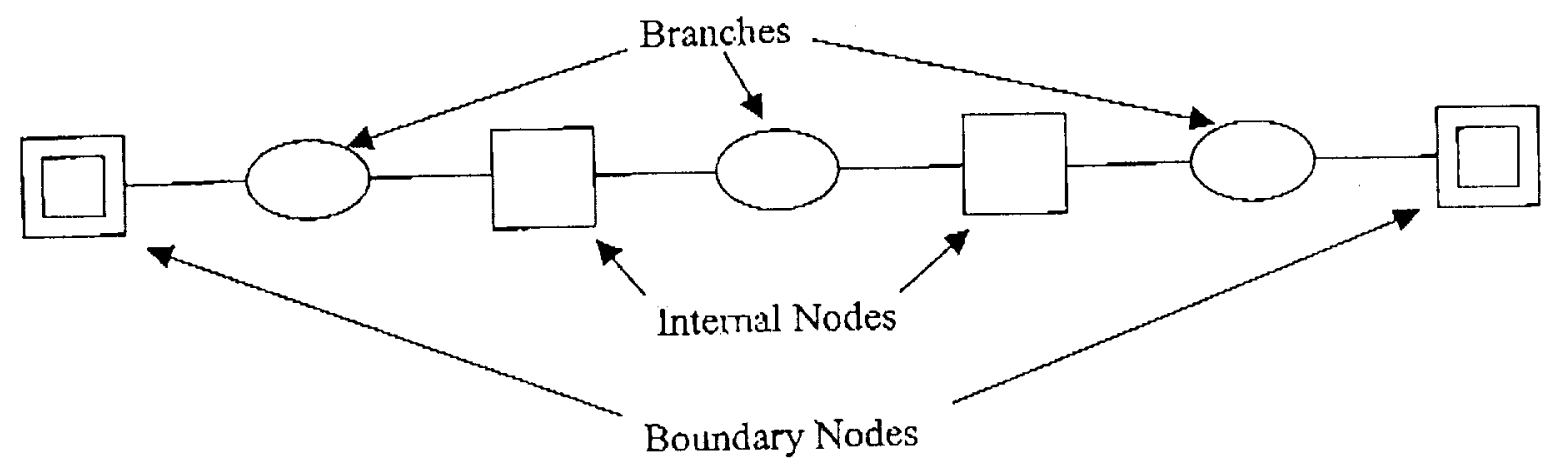

Fig. 4 Flow network consisting of nodes and branches. 


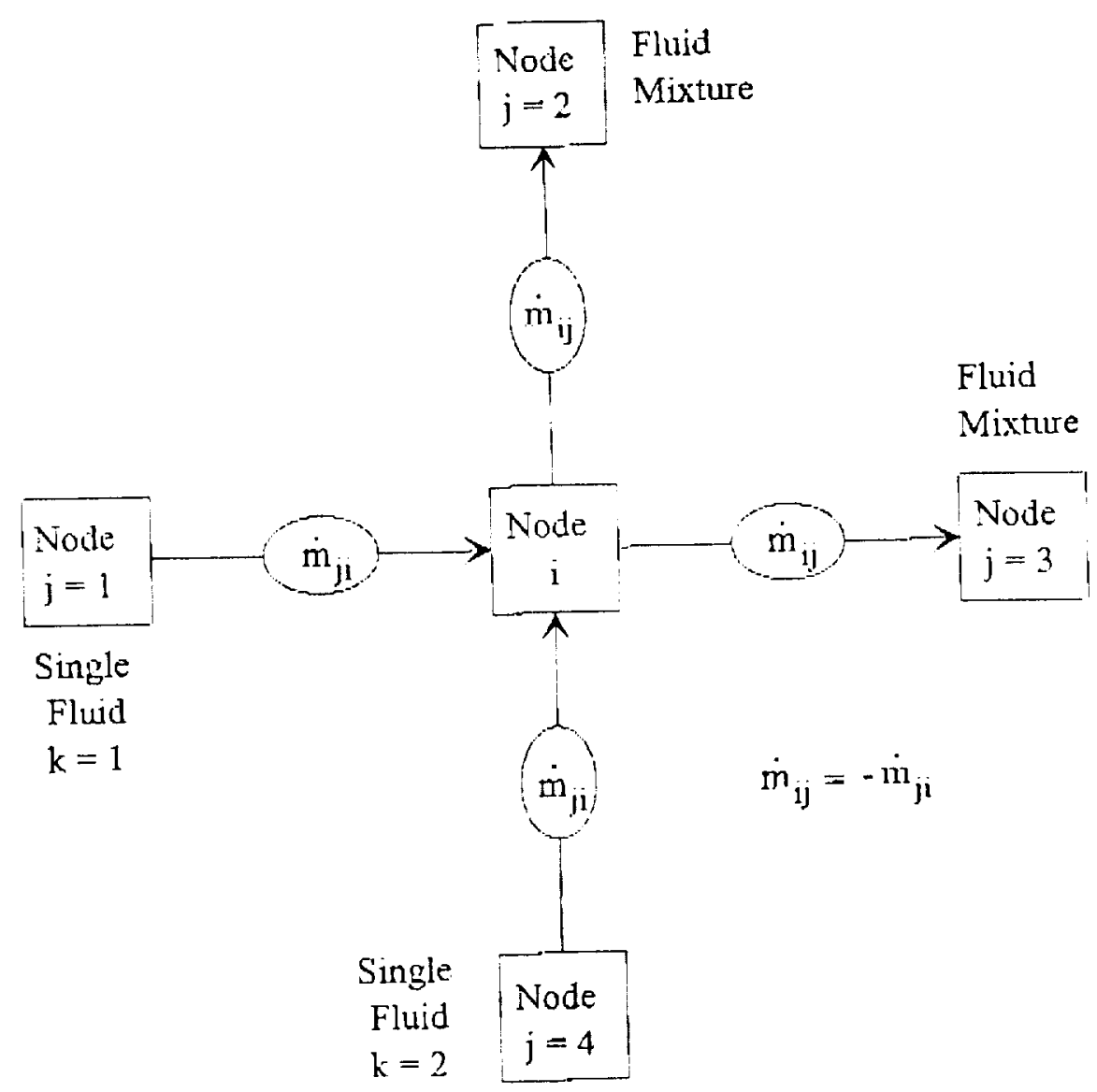

Fig. 5 Schematic of fluid nodes, branches and indexing practice. 


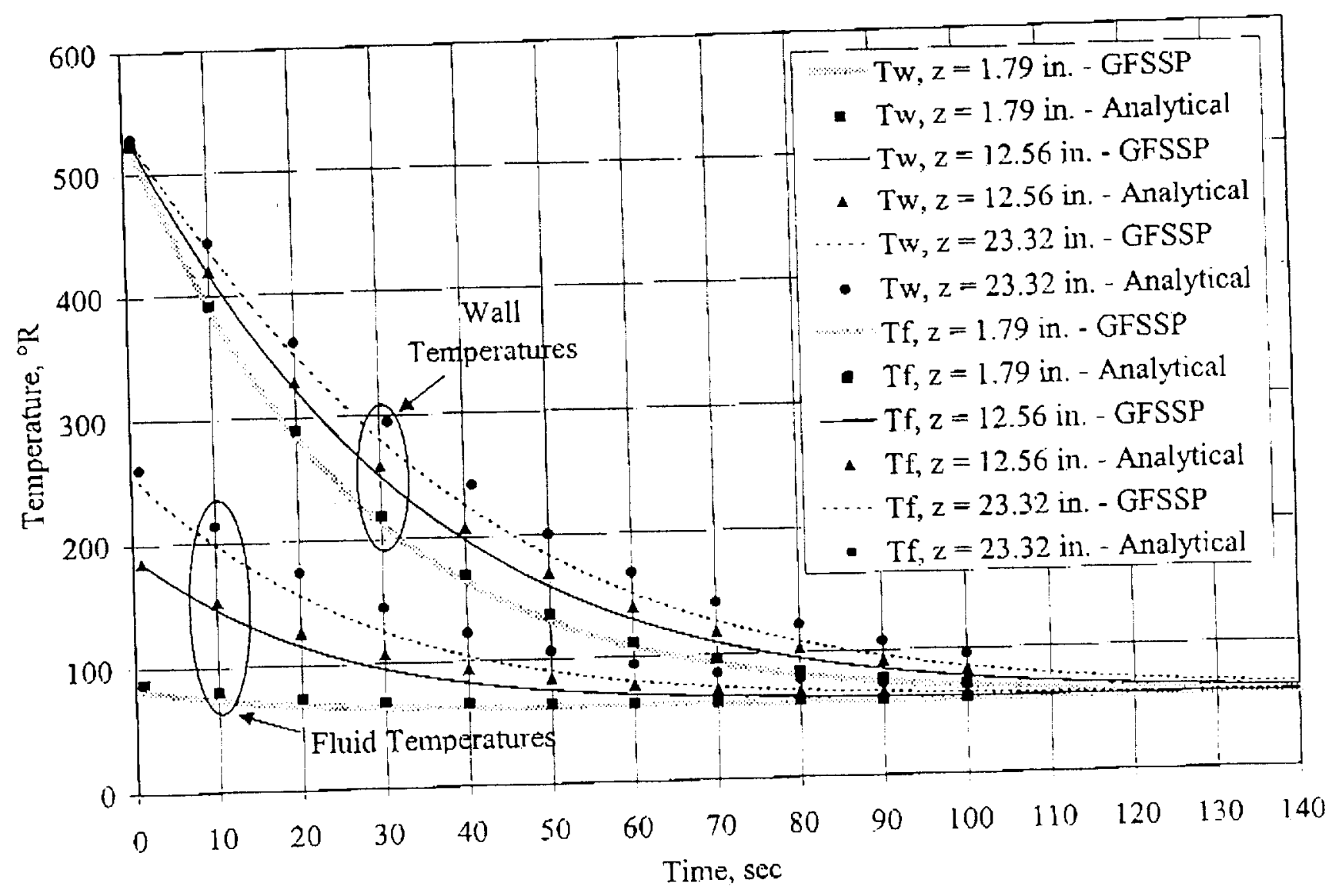

Fig. 6 Comparison of GFSSP-calculated wall and fluid temperatures with temperatures calculated by analytical solution (Model 1: superheated hydrogen, constant h). 


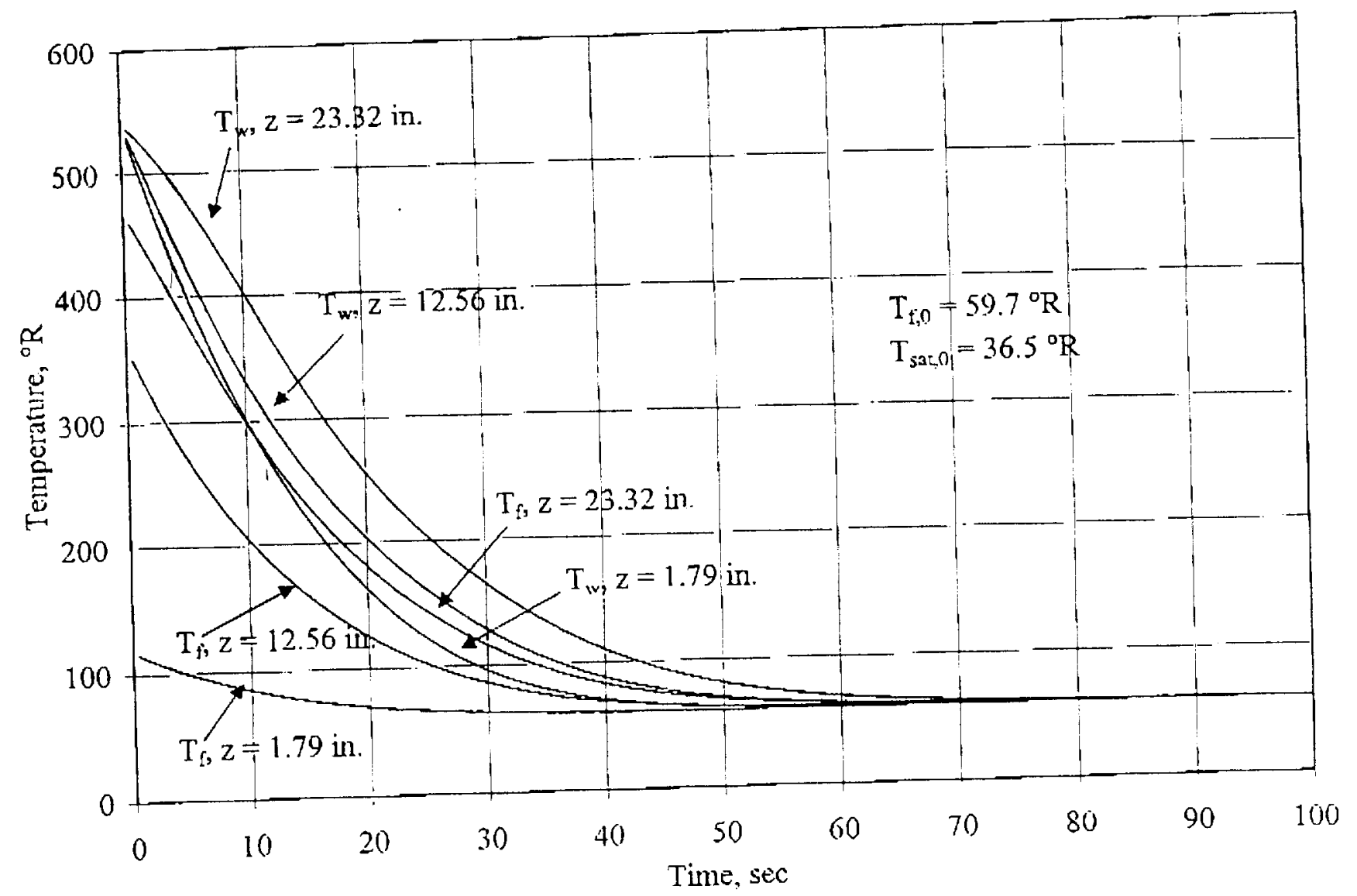

Fig. 7 Temperature vs. time at different avial locations (Model 2: superheated hydrogen, variable $\mathbf{h}$ ). 


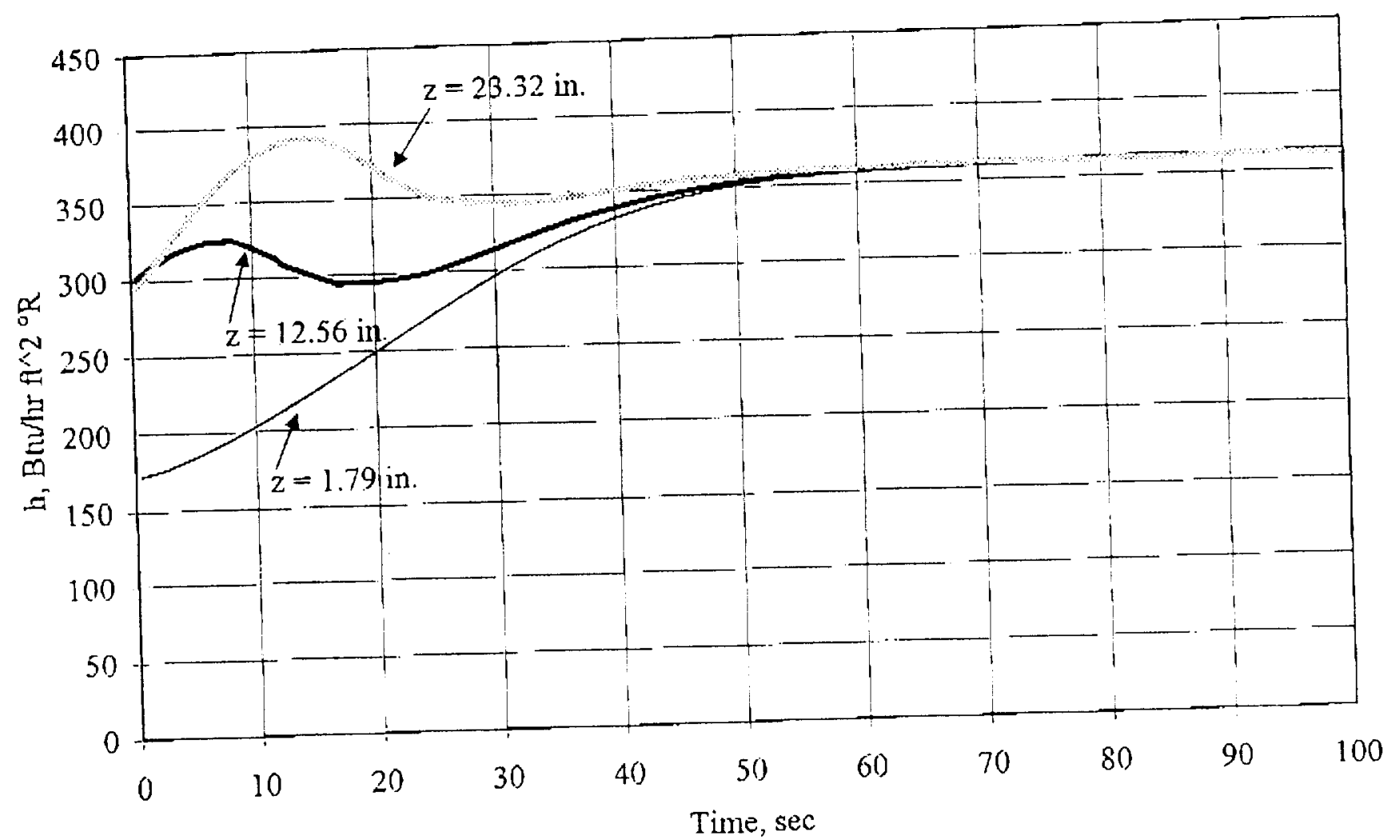

Fig. 8 Heat transfer coefficient vs. time at different axial locations (Model 2: superheated bydrogen). 


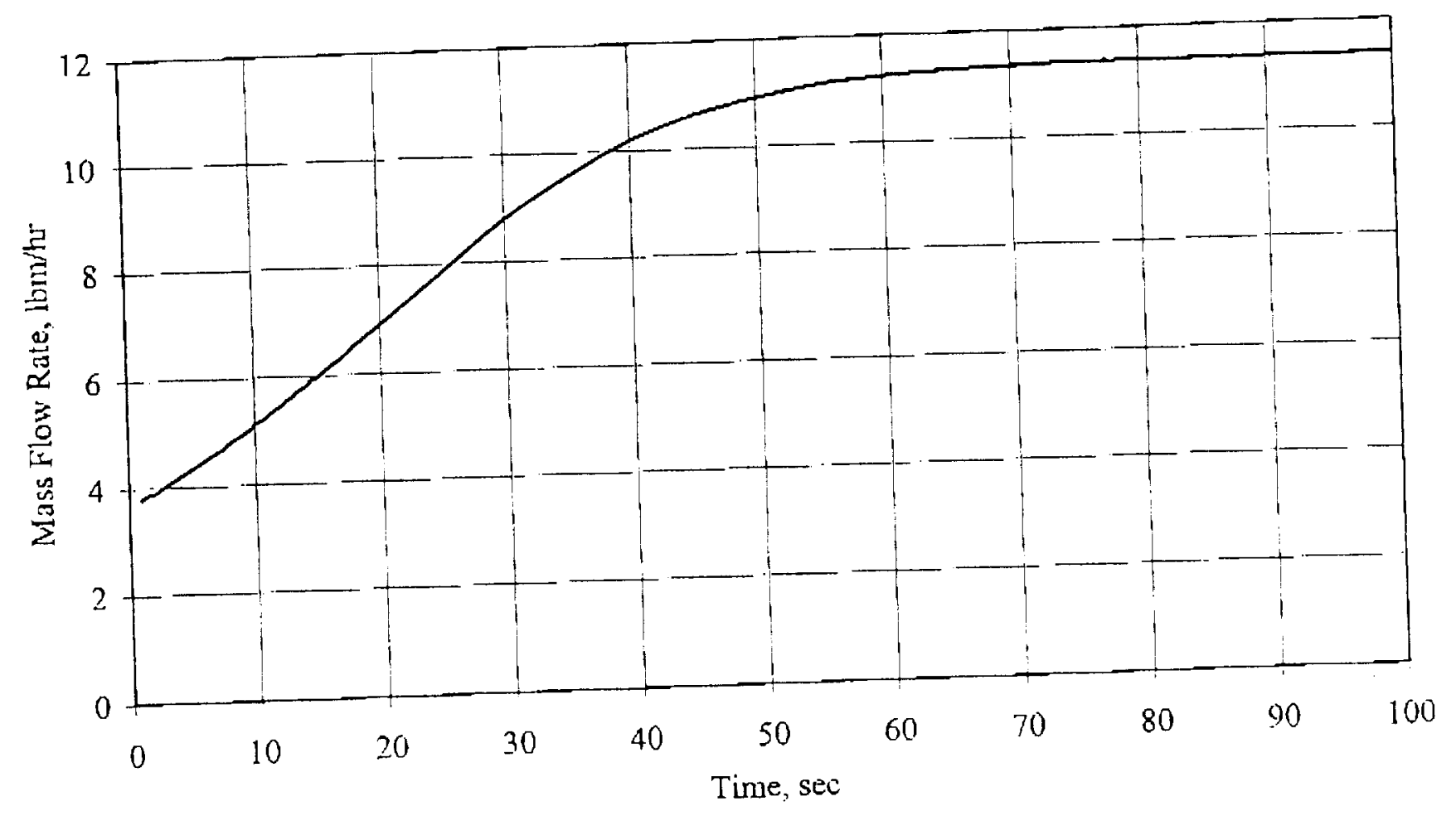

Fig. 9 Mass flow rate vs. time (Model 2: superbeated hydrogen). 


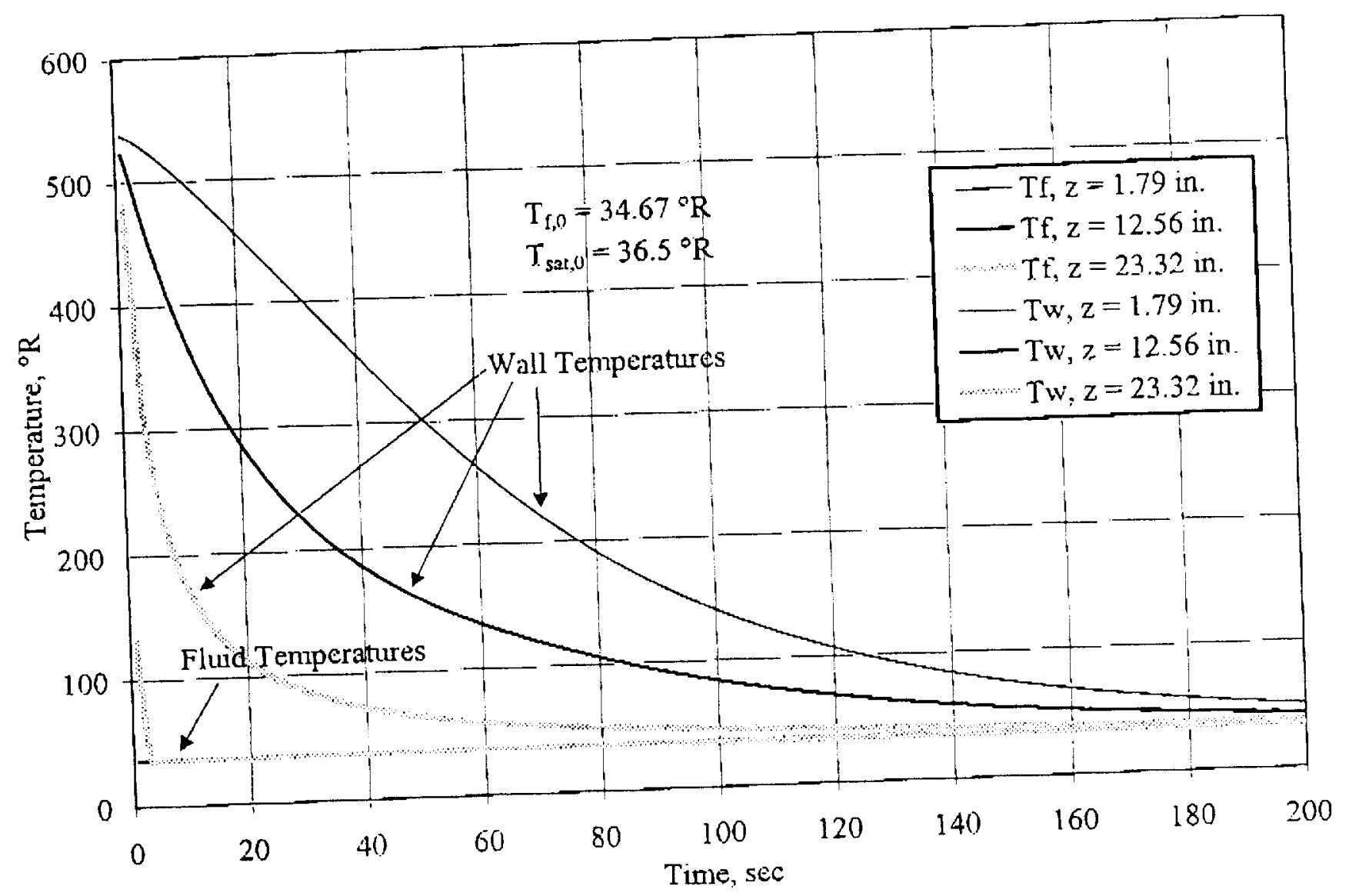

Fig. 10 Temperature vs. time at different axial locations (Model 3: initially subcooled hydrogen, variable $h$ ). 


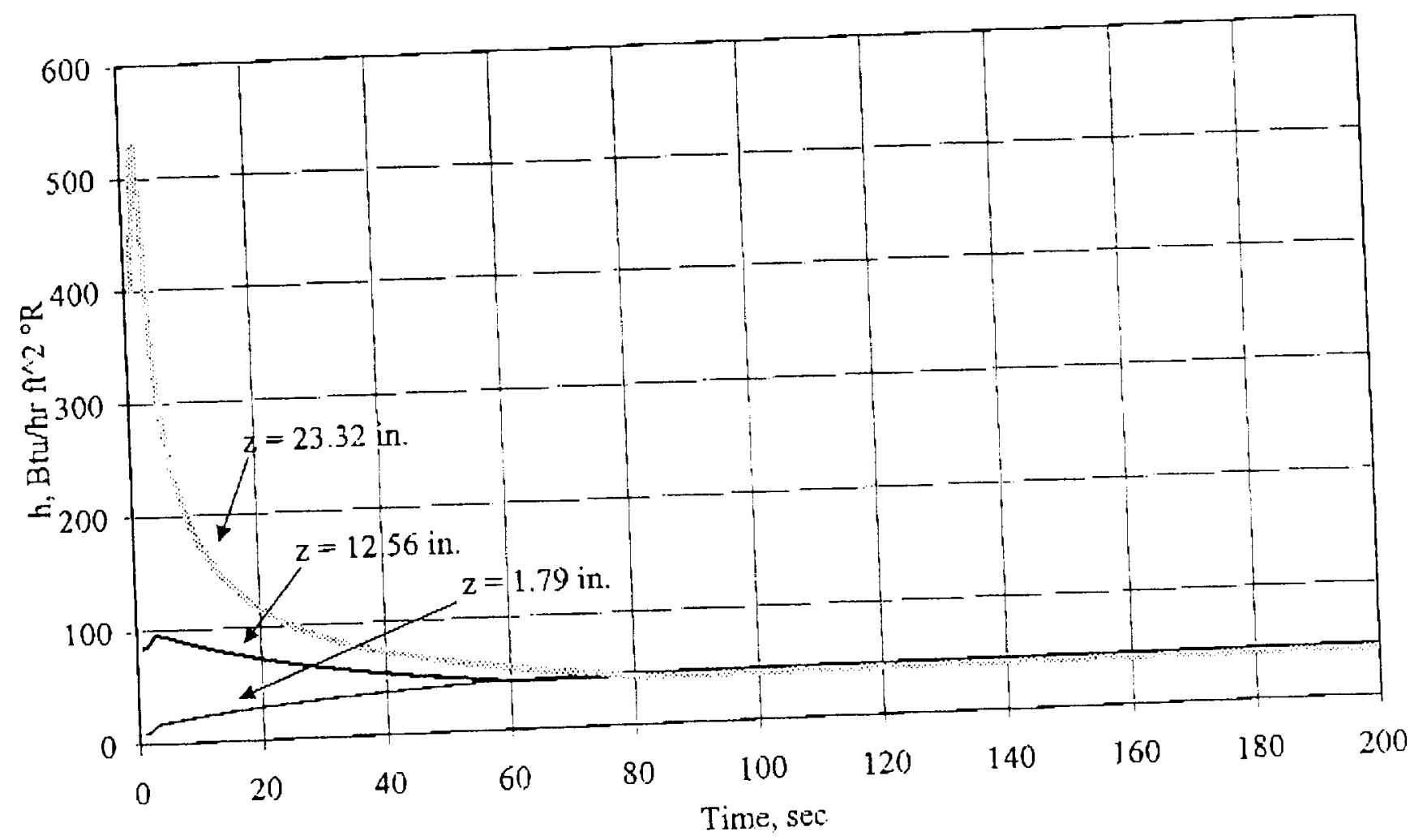

Fig. 11 Heat transfer coefficient vs. time at different axial locations (Model 3: initially subcooled hydrogen). 


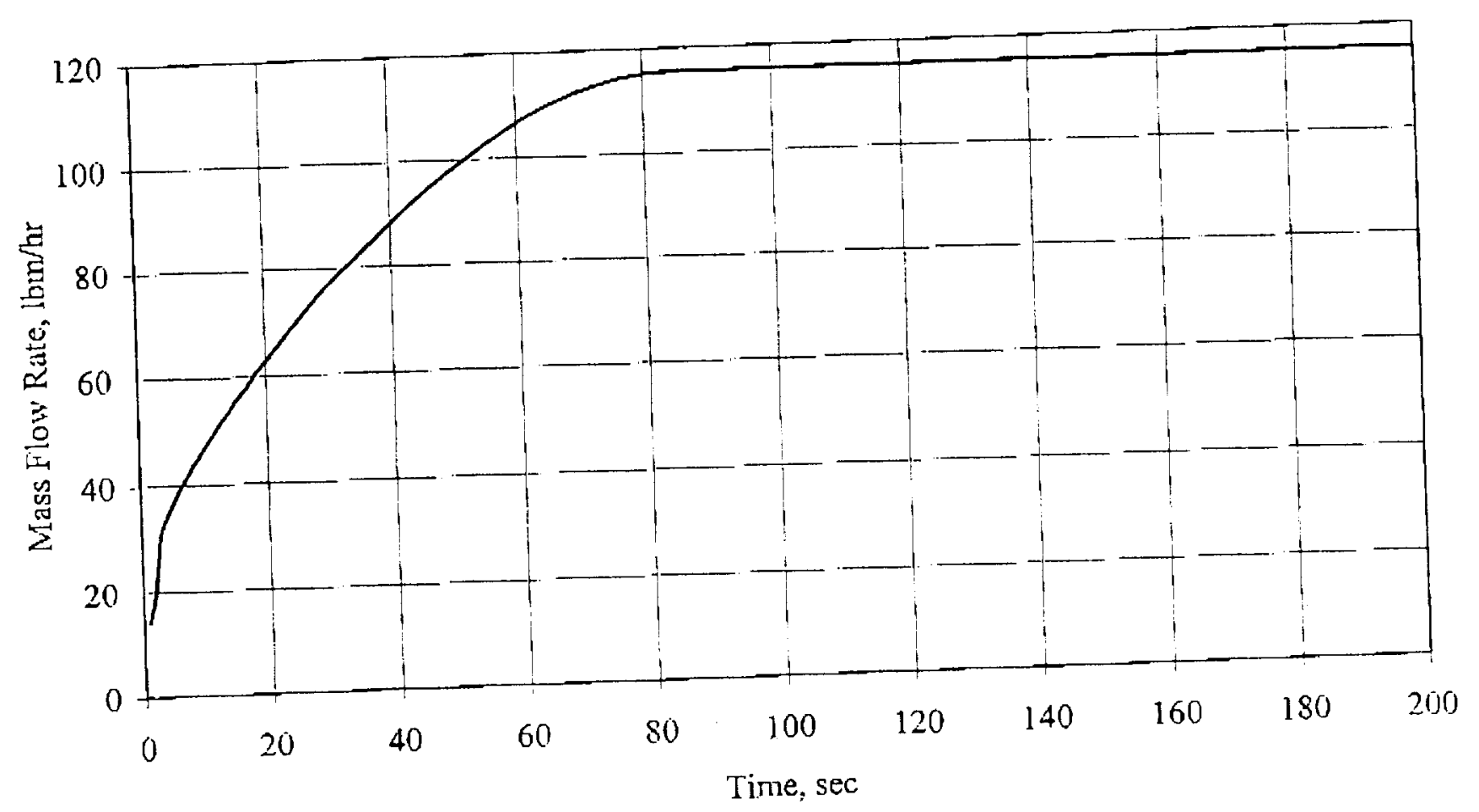

Fig. 12 Mass flow rate vs. time (Model 3: initially subcooled hydrogen). 